\title{
Article
}

\section{Idiopathic radiographic apical root resorption in wind instrument players}

Shafi, Imran and Welbury, Richard

Available at http://clok.uclan.ac.uk/19426/

Shafi, Imran and Welbury, Richard ORCID: 0000-0002-9322-2440 (2015) Idiopathic radiographic apical root resorption in wind instrument players. Dental Update, 42 (10). pp. 972-976. ISSN 0305-5000

It is advisable to refer to the publisher's version if you intend to cite from the work.

For more information about UCLan's research in this area go to

http://www.uclan.ac.uk/researchgroups/ and search for < name of research Group>.

For information about Research generally at UCLan please go to http://www.uclan.ac.uk/research/

All outputs in CLoK are protected by Intellectual Property Rights law, including Copyright law. Copyright, IPR and Moral Rights for the works on this site are retained by the individual authors and/or other copyright owners. Terms and conditions for use of this material are defined in the policies page.

\section{CLoK}

Central Lancashire online Knowledge www.clok.uclan.ac.uk

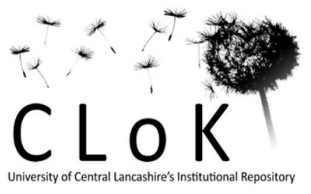


Idiopathic Radiographic Apical Resorption in Wind Instrument Players

Shafi I, Welbury R. Dental Update 2015;42:972-976

\section{Introduction}

Root resorption of the permanent teeth is a pathological process, which can be of internal or external origin. ${ }^{1}$ It involves an elaborate interaction among inflammatory cells resulting in loss of hard dental tissue (cementum or dentine). This is mainly the consequence of osteoclastic cell action. ${ }^{2}$ There are two types of internal resorption: root canal (internal) replacement resorption and internal inflammatory resorption, involving loss of the predentine and odontoblast in the root canal system. ${ }^{3}$

External resorption, which is removal of pre cementum and cementoblasts on the root, can be classified into four categories by its clinical and histological manifestations: external surface resorption, external inflammatory root resorption, replacement resorption, and ankylosis. External inflammatory root resorption can be further categorised into cervical resorption with or without a vital pulp (invasive cervical root resorption) and external apical root resorption. Other variations of resorption include combined internal and external resorption and transient apical breakdown. ${ }^{4}$

Aetiology of root resorption Aetiological factors implicated in external root resorption include: ${ }^{1}$

1 Reimplantation of teeth

2 Orthodontic treatment

3 Eruption of neighbouring teeth

4 Trauma

5 Pulp necrosis

6 Pathology

7 Heredity

8 Parafunctional habits 
Pulp canal obliteration (PCO), also called calcific metamorphosis, is a sequelae of tooth trauma. It more commonly occurs in teeth with concussion and luxation injuries. ${ }^{5-6}$ The response of the pulp to trauma is characterised by deposition of hard tissue in the root canal space resulting in the root canal being less discernable on radiological examination. The crown of the affected tooth may become darker in colour when compared with normal adjacent teeth, because of the greater thickness of dentine, leading to a decrease in translucency. These teeth are often asymptomatic with no periapical pathology. The response to sensitivity tests may be normal in the early stages of PCO, but absent in later stages. ${ }^{6}$ A radiographic study evaluating 276 teeth with pulp canal obliteration found that $30.7 \%$ had a normal periapical appearance on radiographs, $36 \%$ presented with small changes in the periapical bone pattern and $33.3 \%$ had developed periapical lesions. ${ }^{7}$

Historically there has been an assumption that the forces produced in playing wind or brass instruments have an influence on the dentition..$^{8,9}$ Moreover, this speculation was divided into whether these forces were beneficial in correcting orthodontic malocclusions or had detrimental effects. ${ }^{10-12}$ The effect on the hard tissues is dependant on the application of the instrument to the mouth, called an embouchure, and the force produced playing the instrument. An embouchure is use of the instrument player's circum-facial oral muscles and the manner of application of the lips and teeth to the mouthpiece of musical wind instrument. ${ }^{13}$ There are several sub types, and it takes long term commitment and practice by the player to be completely proficient in its formation and use. Embouchure variations mean that there are a multitude of soft tissue applications to differing mouthpieces. The only pathology so far associated with an embouchure is dystonia, which is a neurological movement disorder, in which the sustained muscular contractions causes twisting, repetitive movements or abnormal postures. ${ }^{14}$

However reviewing the literature reveals no reports on root morphological changes of the teeth of wind instruments players. The purpose of this paper is to present three cases of radiographic apical root resorption in wind instrument players and the management of their particular cases. 


\section{Case Report 1}

An 18 year old girl was referred to the Orthodontic Department by her orthodontic specialist practitioner due recently diagnosed yellow discolouration of tooth UL1 and the shortened radiographic appearance of the upper incisor roots (Figure 1). Her medical history was unremarkable.

Her previous dental history was significant for orthodontic functional twinblock treatment six years previously. This reduced her overjet and was discontinued after six months of night time retention regime. She then returned to her orthodontic specialist practitioner aged 17 complaining of recurrence of her overjet. Orthodontic treatment involved extraction of upper first premolars and fixed appliance therapy. Following only six weeks of treatment during the aligning and levelling phase discolouration of tooth UL1 was noted. There was no history of dental trauma.

Clinical examination revealed a well maintained dentition. All four maxillary incisors were normal to clinical testing with no signs of infection. The central incisors were grade 1 mobile and periapical radiographs showed pulp canal obliteration and significant external apical root resorption.

Social history revealed that the patient had played the oboe for a four year period and practised regularly on a daily basis.

Orthodontic treatment was discontinued and the preferred treatment option was to restore premolar spaces with fixed cantilever bridgework. This had the advantage of both good aesthetics and avoiding further orthodontic therapy, which may increase the risk of root resorption and hence pose a greater risk to the longevity of the teeth.

\section{Case Report 2}

A 15 year girl had fallen down the stairs at school while holding her trumpet in her mouth. She attended her dentist, and although she complained of no symptoms, examination revealed slight mobility of upper incisors and a palatal acid etch splint 
was placed. An initial diagnosis of subluxation was made. She was then referred to the Child Dental Health Department for further assessment. Her medical history was unremarkable but her dental history revealed trauma to the upper primary incisors at age six. The dental records showed that these teeth were displaced but not avulsed.

Social history revealed that she had played the trumpet since age six and currently plays in an orchestra, with significant regular practice. Clinical examination revealed a well maintained permanent dentition with the anterior teeth exhibiting mild mobility. The teeth responded normally to clinical testing and there were no signs of infection. Periapical radiographs showed that both UR1, UL1 had severely shortened roots, with evidence of the remnants of the previous acid etch splint (Figure 2). The degree of external apical root resorption could not be attributed to the recent trauma, nor to the previous primary trauma although theoretically the primary trauma could have initiated premature root end closure of the permanent incisors. Therefore it is possible that the forces placed on the teeth while playing her instrument may have caused the external resorption.

The patient was concerned about the mobility of her teeth and how this will impact on her trumpet playing. An upper pressure formed $1 \mathrm{~mm}$ thick thermoplastic appliance was constructed (Erkodur®, Erkodent, Pfalzgrafenweiler, Germany) to stabilise the anterior teeth while playing to minimise any further resorption.

However premature loss of the central incisors is predicted in the short to medium term and implant placement is likely to be the long term solution.

\section{Case Report 3}

An 11 1/2 year old female was referred to the Child Dental Health department after trauma to her upper incisors sustained during a clash of heads in the playground. She initially attended her general dental practitioner who diagnosed subluxation injuries of 
teeth UR1, UL1. Periapical radiographs were taken which revealed that the roots of both these teeth were far shorter than the lateral incisors and the practitioner referred the patient to the department.

On examination she was in the full permanent dentition with the exception of third molars. Her oral hygiene was excellent and she had a well maintained sound dentition. A $2 \mathrm{~mm}$ midline diastema between the upper central incisors was noted which apparently had always been present. Clinical examination of the upper permanent incisors was normal. The only clinical symptom noted was a slight increase in mobility associated with UR1, UL1. Periapical radiographs confirmed that both central incisors had lost half of their root length in comparison to the lateral incisors, which were normal (Figure 3). No pathology was visible and the appearance resembled external apical root resorption.

There was no previous history of trauma; orthodontic treatment or habits. However the patient confirmed that she had begun playing the trumpet two years ago and had been practicing on a daily basis since then. From the extensive history ascertained, this was the only activity in which the patient could have been exerting forces on her upper incisors.

The patient was keen to continue playing the trumpet and hence a thermoplastic upper pressure formed appliance was constructed (Figure 4). She is able to wear this while playing the trumpet with no obvious detrimental effect on her ability.

\section{$\underline{\text { Discussion }}$}

There has been a classification of wind instruments mouthpieces, initially developed for the unproven beneficial effects in certain malocclusions. However the categorisation is useful as it illustrates the embouchure. ${ }^{15}$ 
- Class A- All cup-shaped mouthpieces, as in the trumpet, trombone, tuba, all horns, and brasses.

- Class B - Single-reed mouthpieces, as in the clarinet and the saxophone.

- Class C - Double-reed mouthpieces, as in the oboe and bassoon.

- Class D - Mouthpieces with a small aperture or opening at the head, as in the flute and piccolo.

Instruments differ widely in mouthpiece diameter and pitch, and hence there is a range in mouthpiece forces and lip tensions required to produce a sound.

Cross sectional and longitudinal studies investigating wind instruments and the dentition have looked at mainly orthodontic clinical signs including: incisor classification, malocclusion, overjet, overbite and centreline. These have provided conflicting results, with the majority of studies concluding that long term wind instrument playing may have some effect on the dentition, but are generally inconclusive. $^{16,17}$

Moreover these studies were undertaken in growing populations with varied musical experience, and time duration playing instruments was poorly quantified. Outcome measures were chronological study models, and hence static occlusions. ${ }^{19}$

Radiographic assessments were lateral cephalometric radiographs, and again looking at cephalometric changes rather than root morphology. ${ }^{19,20}$ A recent study looking at orthodontic study casts concluded that, though playing wind instrument did not significantly influence the position of anterior teeth or was an aetiological factor in malocclusion development, playing a brass instrument with a large cup-shaped mouthpiece may predispose to buccal crossbite development. ${ }^{21}$

The embouchure of a wind instrument involves the exerting of forces on the soft and hard tissues. However the size, direction and manner of forces produced are dynamic and complex. Quantifying these forces while the instrument is being played have concentrated on measuring activity of the muscles concerned, pressure in the oral cavity, and mouthpiece forces. ${ }^{22-24}$ Trumpet playing forces shown by an intra oral 
device ranged from 10-50 Newtons (100-500 grams) being dependant on the note played, amount and duration of force and proficiency of the musician. ${ }^{25}$ Orthodontic appliances generally require $30 \mathrm{~g}$ to tip teeth for a removable appliance with up to $100 \mathrm{~g}$ of force to bodily move teeth for fixed appliances.

However any device constructed to measure wind instrument forces, whether attached to the mouthpiece or intra oral, may impede either embouchure or tone formation. The actual distribution of mouthpiece forces and lip tension forces acting on the hard tissues are unknown, but lip tension may be of major importance in stressing the incisors during brass instrument playing. ${ }^{24,25}$ Moreover, maxillary permanent central incisors have exhibited horizontal deflections of up to $100 \mu \mathrm{m}$ during wind instrument playing. ${ }^{23}$

Orthodontically induced inflammatory root resorption has been implicated with: continuous vibratory forces and intermittent forces; and vibratory forces causing occlusal trauma. ${ }^{26-28}$ Furthermore, of all the different types of tooth movements possible, intrusive force applications has been found to significantly increase orthodontically induced inflammatory root resorption rates compared with controls. 29,30

The Clinical Standards Committee of the British Orthodontic Society has produced an advice sheet with respect to braces and wind instruments for patients. It discusses both removal and fixed appliances, explaining that orthodontic treatment may affect the patients' ability to practice and perform. It advises patient to arrange fitting of an orthodontic appliance at a time that avoids important music exams, auditions or performances. It concludes that there will be some temporary effect of their musical performance including: dry mouth; soft tissue trauma and inability to achieve certain high notes. However with practice and motivation most wind instrument players adjust to wearing braces. ${ }^{31}$

Conventional dental panoramic radiographic investigation to assess root lengths is hindered in the anterior maxillary region because of the focal trough. It is a relatively narrow region in the incisor region, therefore the apices and associated structures can be out of focus or even invisible. ${ }^{32}$ Routine periapical radiographs for orthodontic 
assessment is unjustified unless: clinical examination suggest the presence of an abnormality; interceptive and active orthodontic treatment is being considered assessment for prior trauma. ${ }^{33,34,35}$ However current guidelines do not consider habits, with potentially a cohort of patients with undiagnosed anterior root resorption undergoing orthodontic therapy.

\section{Conclusion}

Wind instrument playing produces adequate forces, tooth deflection and time required for an environment to expose the teeth to non physiological orthodontic forces. It could be speculated that instrument players, who have been playing and practicing over many years, produce vibratory forces within the periodontium. This mimics oscillating orthodontic movements causing increase risk of root resorption. Therefore, additional questioning about musical wind instrument playing during case history taking would be beneficial to clinicians. Furthermore, careful clinical monitoring of these patients' teeth during their treatment should be undertaken, as the additive effects of orthodontics and their musical habit may increase the risk of root resorption.

Figure 1 Periapical radiographs of UR1 (a) and UL1 (b) showing patient in fixed appliances with moderate root resorption and blunt apices. 
(a)

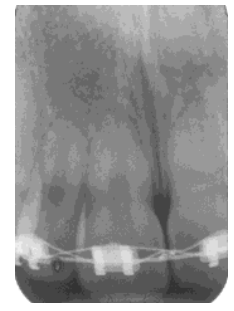

(b)

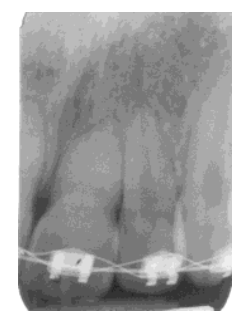

Figure 2 Periapical radiographs of UR1 (a) and UL1 (b) showing patient with severe root resorption, blunt apices and remnants of composite adhesive used for splinting the teeth placed by the dentist. The patient was seen within two weeks of the initial referral by the dentist.

(a)

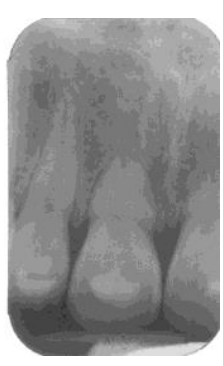

(b)

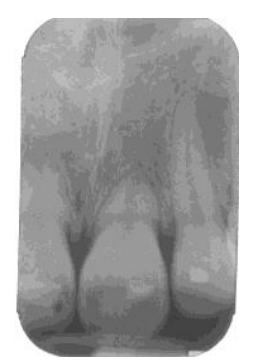

Figure 3 Periapical radiographs of UR1 (a) and UL1 (b) showing patient with severe root resorption and blunt apices.

(a)

(b)
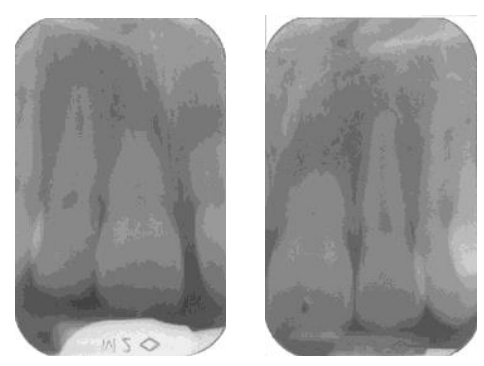

Figure 4 (a, b) Thermoplastic upper pressure formed appliance in situ. Patient wears this when playing wind instrument with no detrimental effects on ability.

(a) 

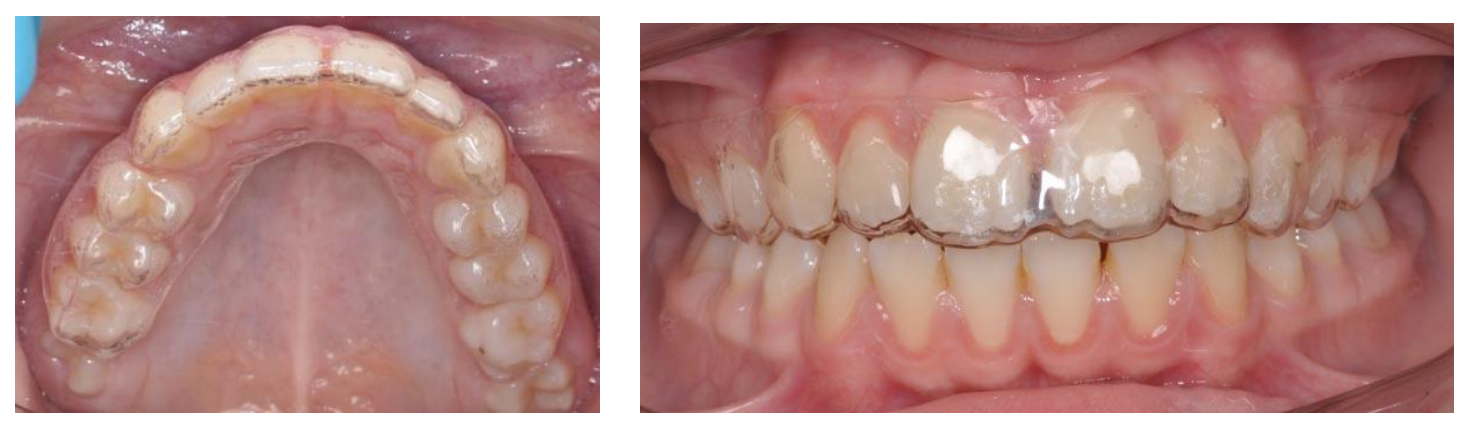


\section{$\underline{\text { References }}$}

1 Barclay CW. Root resorption: aetiology, classification and clinical management. Dent Update 1993; 20: 248-50.

2 Patel S, Ford TP. Is the resorption external or internal? Dent Update 2007; 34: 218-29.

3 Gunraj MN. Dental root resorption. Oral Surg Oral Med Oral Pathol Oral Radiol Endod 1999; 88: 647-53.

4 Ne RF, Witherspoon DE, Gutmann JL. Tooth resorption. Quintessence Int 1999; 30: 9-25.

5 Oginni AO, Adekoya-Sofowor CA. Pulpal sequelae after trauma to anterior teeth among adult Nigerian dental patients. BMC Oral Health 2007; 7: 11-5.

6 Patterson S, Mitchell D. Calcific metamorphosis of the dental pulp. Oral Surg Oral Med Oral Pathol 1965; 20: 94-101.

7 Oginni AO, Adekoya-Sofowora CA, Kolawole KA. Evaluation of radiographs, clinical signs and symptoms associated with pulp canal obliteration: an aid to treatment decision. Dent Traumatol 2009; 25: 620-5.

8 Lamp CJ, Epley FW. Relation of tooth evenness to performance on brass and woodwind musical instruments. J. Am. Dent Assoc 1935; 22: 1232-36.

9 Hruby A, Kessler HE. Dentistry and Musical Wind Instrument Problem. Dent Radiogr Photogr 1959; 32: 1-8.

10 Heskia JE, Hospital I. Musical Wind Instruments Utilized in Orthodontics. Dent Abst 1957; 2: 67.

11 Kessler HE. Dental Study of a Professional Trumpet Player. J Am Dent Assoc 1959; 59: 320-21. 
12 Porter MM. Dental problems in wind instrument playing. 1. Dental aspects of the embouchure. Br Dent J 1967; 123: 393-96

13 Kennedy M, Bourne J. The Concise Oxford Dictionary of Music. $5^{\text {th }}$ Edition. Oxford: Oxford University Press 2007.

14 Frucht SJ, Fahn S, Greene PE, et al. The natural history of embouchure dystonia. Mov Disord 2001; 16: 899-906.

15 Strayer E R. Musical instruments as an aid in the treatment of muscle defects and perversions. Angle Orthod 1939; 9:18.

16 Gualtieri PA. May Johnny or Janie play the clarinet? The Eastman Study: a report on the orthodontic evaluations of college-level and professional musicians who play brass and woodwind instruments. Am J Orthod 1979; 76: 260-76.

17 Pang A. Relation of musical wind instruments to malocclusion. J Am Dent Assoc 1976; 92: 565-70.

18 Herman E. Influence of musical instruments on tooth positions. Am J Orthod 1981; 80: 145-55.

19 Fuhrimann S, Schüpbach A, Thüer U, et al. Natural lip function in wind instrument players. Eur J Orthod 1987; 9: 216-23.

20 Brattström V, Odenrick L, Kvam E. Dentofacial morphology in children playing musical wind instruments: a longitudinal study. Eur J Orthod 1989; 11: $179-85$.

21 Grammatopoulos E, White AP, Dhoptakar A. The Effects of Playing a Wind Instrument on the Occlusion. J Orthod 2010; 37:308. 
22 White ER. Electromyographic potentials of selected facial muscles and labial mouthpiece pressure measurements in the embouchure of trumpet players. [Doctoral thesis] Columbia University, New York: 1972.

23 Henderson HW. An experimental study of trumpet embouchure. J Acoust Sot Amer 1942; 13: 58-64.

24 Barbenel JC, Kenny P, Davies JB. Mouthpiece forces produced while playing the trumpet. J Biomech 1988; 21: 417-24.

25 Borchers L, Gebert M, Jung T. Measurement of tooth displacements and mouthpiece forces during brass instrument playing. Med Eng Phys 1995; 17: 567-70.

26 Hall A. Upper incisor root resorption during Stage II of the Begg technique. Br J Orthod 1978; 5: 47-50.

27 Baumrind S, Korn EL, Boyd RL. Apical root resorption in orthodontically treated adults. Am J Orthod Dentofac Orthop 1996; 110: 311-20.

28 Linge BO, Linge L. Apical root resorption in upper anterior teeth. Eur J Orthod 1983; 5: 173-83.

29 Han G, Huang S, Von den Hoff JW, et al. Root resorption after orthodontic intrusion and extrusion: an intraindividual study. Angle Orthod 2005; 75: $912-$ 8.

30 Harris DA, Jones AS, Darendeliler MA. Physical properties of root cementum: part 8. Volumetric analysis of root resorption craters after application of controlled intrusive light and heavy orthodontic forces: a microcomputed tomography scan study. Am J Orthod Dentofacial Orthop 2006; 130: 639-47.

31 Advice for musicians. Clinical Standards Committee of the British Orthodontic Society 2007. 
32 Isaacson KG, Thom AR, Horner K, Whaites E. Orthodontic radiographs guidelines. $3^{\text {rd }}$ Edition. British Orthodontic Society 2008.

33 Faculty of General Dental Practitioners (UK). Selection Criteria for Dental Radiography. London, Royal College of Surgeons of England. 2004

34 The Ionising Radiation (Medical Exposure) Regulations. IR(ME)R. London, Her Majesty's Stationery Office 2000.

35 European guidelines on radiation protection in dental radiology. The safe use of radiographs in dental practice. Radiation Protection 136. European Commission 2004. 